\title{
Editorial
}

Dermatology

\section{Chloracne, a Misnomer and Its Implications}

\author{
J.H. Saurat O. Sorg \\ SCAHT - Dermatotoxicologie, Centre Médical Universitaire, Geneva, Switzerland
}

In this issue, Passarini et al. [1] report on an outbreak of so-called chloracne in Italy. This article importantly reminds us of the many issues that relate to human dermatotoxicology in general and dioxin exposure in particular.

The skin is a key organ for the recognition of exposure to several poisons, and more specifically those related to the dioxin group. Such a 'sentinel' role for the skin is most probably related to the fact that many poisons, introduced either through the skin or systemically, are metabolized in the skin and therein induce symptoms that may be specific for that poison. It was through the thoughtful clinical and histological analysis of the Italian group from the dermatology department of Bologna that a diagnosis of 'chloracne' was made in several patients having been intoxicated in a holiday resort. For such a diagnosis, high clinical suspicion and specific laboratory markers are necessary, since important ecotoxicology issues may be involved.

So how robust is the diagnosis of 'chloracne' in this case series from Passarini et al. [1], and where are the guidelines for the minimum mandatory criteria for such a diagnosis?

\section{KARGER \\ Fax +4161306 1234 \\ E-Mail karger@karger.ch}

www.karger.com
(C) 2010 S. Karger AG, Basel

$1018-8665 / 10 / 2211-0023 \$ 26.00 / 0$

Accessible online at: www.karger.com/drm

\section{The Clinical Aspect Is Not Diagnostic}

For the trained clinician, 'chloracne' is one of the differential diagnoses when an acneiform rash develops in a previously non-acneic patient. Yet there has been so far no clinical sign specific for 'chloracne' that would not be present in some patients with either 'spontaneous' or exogenous acne. Most of the descriptions in the literature either on sporadic or epidemic cases do not provide us with a robust red light that would trigger the specific ecotoxicology diagnostic process.

The current knowledge rather focuses on histology, which appears to provide a key robust, reproducible and specific sign, i.e. the disappearance of sebaceous glands.

\section{Skin Histology Is Mandatory and Provides Strong Arguments for Diagnosis}

There are two major signs that had been well described but perhaps not assigned their proper diagnosis weight. It is our view that new unique constellation signs, both a structure addition and a structure loss, with the respect

Prof. Jean-Hilaire Saurat

SCAHT - Dermatotoxicologie, Centre Médical Universitaire 1 rue Michel-Servet

$\mathrm{CH}-1211$ Genève 4 (Switzerland)

E-Mail Jean.Saurat@unige.ch 
Fig. 1. Structure of known AhR agonists. FICZ = 6-formylindolo[3,2-b]carbazole; $\mathrm{HCN}=$ hexachloronaphthalene; $\mathrm{PeCB}=$ pentachlorobiphenyl; $\mathrm{PeCDF}=$ pentachlorodibenzofuran; TCDD = tetrachlorodibenzo-p-dioxin.<smiles>Clc1cc2c(cc1Cl)Oc1cc(Cl)c(Cl)cc1O2</smiles>

$2,3,7,8-\mathrm{TCDD}$

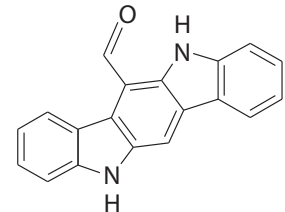

FICZ

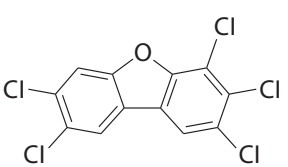

2,3,4,7,8-PeCDF<smiles>Clc1cc2c(Cl)c(Cl)c(Cl)c(Cl)c2cc1Cl</smiles>

$1,2,3,4,6,7-\mathrm{HCN}$

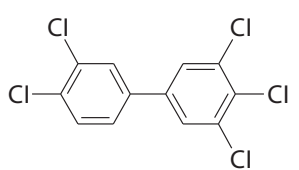

$3,3^{\prime}, 4,4^{\prime}, 5-\mathrm{PeCB}$

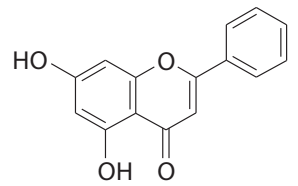

Chrysin and conservation of most other features, are the specific hallmark of dioxin toxicity in the skin.

The structure loss is of key importance. It is the disappearance of the sebaceous glands. This has been repeatedly indicated $[2,3]$ but perhaps not sufficiently emphasized as a key, almost diagnostic, feature. In human pathology there is no other example where sebaceous glands do vanish, which gives quite a weight to this observation.

The term 'chloracne' is therefore a misleading misnomer: these lesions are not 'acne' because there is no sebaceous gland hypertrophy, but rather the disappearance of sebaceous glands $[2,3]$.

The structure addition is the presence of epidermal cysts, either superficial, with an open comedo-like aspect, or deeper in the dermis. The ontogeny, histologically specific characters, focal expression of dioxin-metabolizing cytochrome P450 enzymes and dioxin storage potential of these cysts are described elsewhere [Saurat et al., in preparation]. Based on the observations made in a case of massive dioxin poisoning [4], we have proposed to call these dioxin-induced cysts 'metabolizing acquired dioxin-induced skin hamartomas' (MADISH).

The newly identified phenotypic attributes of these MADISH [Saurat et al., in preparation], when confirmed in more than one paradigm case, may become a key diagnostic item of dioxin exposure in humans.

From this we can confirm that the case series from Passarini et al. fulfills the currently accepted clinicopathological criteria that should trigger - as the authors wrote - 'environmental inquiry to detect potential contamination by dioxins and polychlorinated biphenyls'.
Unfortunately, despite all their efforts, they could not demonstrate such a contamination. This is likely related to the complexity of the problem and the inappropriateness of the current diagnostic procedures aiming at demonstrating harmful exposure of humans to dioxins.

Where are the problems?

\section{Demonstration of the Poison: Direct Dosing and Biological Signs of Exposure}

Facing a suspicion of 'chloracne' (better say MADISH) in a patient, the so-called chloracnegens can be assessed in serum and various tissues by direct chemical analysis or a biological assay [5]. The chemical analysis is performed by gas chromatography with high-resolution mass spectrometry and gives the precise value for each chloracnegen analyzed, usually 7 polychlorinated dibenzodioxins (PCDD) and 10 polychlorinated dibenzofurans (PCDF), then the global amount of chloracnegens is given as 2,3,7,8-tetrachlorodibenzo-p-dioxin equivalent (TEQ), using the 2,3,7,8-tetrachlorodibenzo- $p$-dioxin equivalent factor (TEF) for each analyte [4]:

$$
\mathrm{TEQ}=\sum_{\mathrm{i}} \mathrm{PCDD}_{\mathrm{i}} \cdot \mathrm{TEF}_{\mathrm{i}}+\sum_{\mathrm{j}} \mathrm{PCDF}_{\mathrm{j}} \cdot \mathrm{TEF}_{\mathrm{j}}
$$

Since these compounds are very lipophilic, the value is usually expressed as lipid weight, rather than as wet weight. This method requires a sophisticated equipment, a complex methodology, is very expensive and gives only the results for the particular chemicals that were analysed, i.e. it is possible to miss a chloracnegen 
Fig. 2. Diagram illustrating the mode of action of dioxin-like compounds. Arnt = AhR nuclear translocator; hsp90 $=90-\mathrm{kDa}$ heat shock protein; XAP2 = hepatitis $\mathrm{B}$ virus $\mathrm{X}$-associated protein; $\mathrm{XRE}=$ xenobiotic response element.

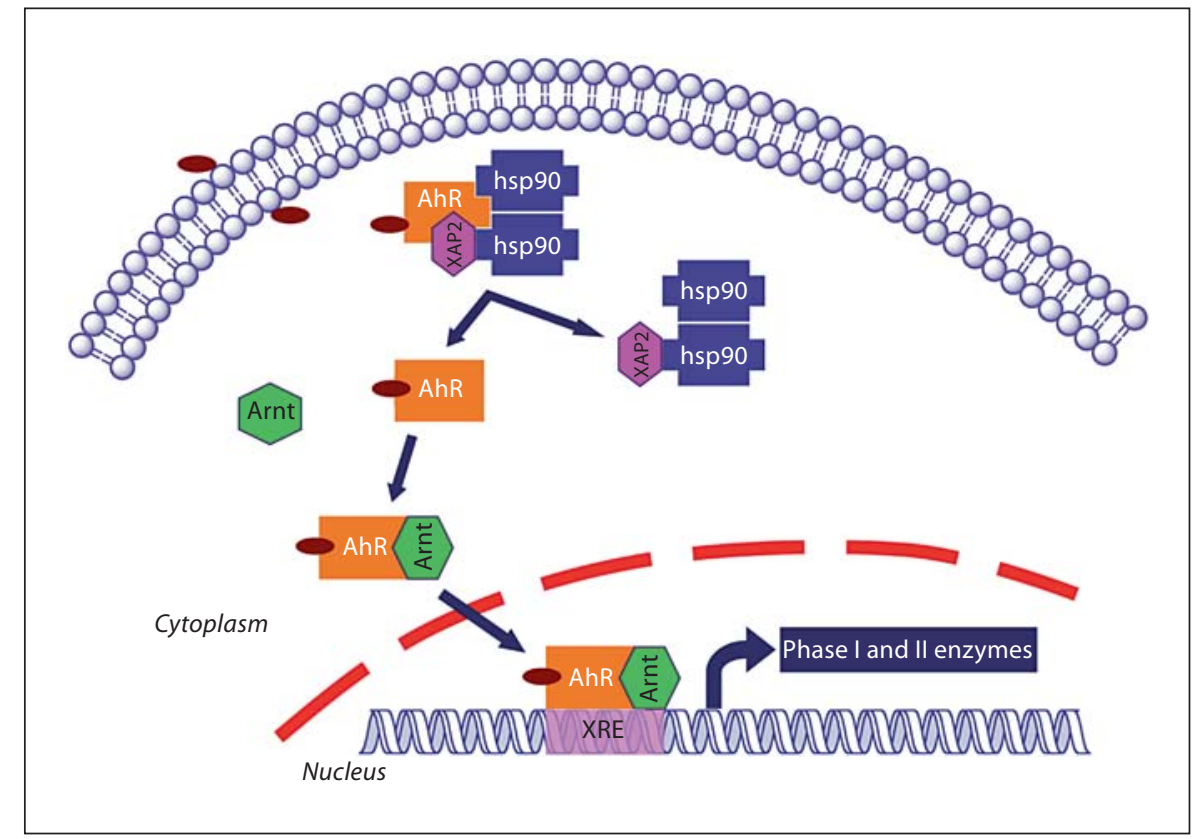

that does not belong to the list of the chemicals analysed. However, the advantage of this method is the knowledge of the nature of the chemicals participating in the syndrome. The alternative method, dioxin-responsive chemically activated luciferase expression, is based on the hypothesis that chloracnegens act via their binding to the intracellular aryl hydrocarbon receptor (AhR) and the activation of DNA sequences called xenobiotic response elements found in the promoter region of inducible genes [6] (fig. 1, 2). A special cellular construction using Photinus pyralis luciferase as the reporter gene allows to assess the global activation of AhR ligands applied to the cells. This method has the advantage to give the global activation of the AhR pathway, expressed as TEQ, whatever the nature of all AhR ligands involved in the syndrome. Thus, gas chromatography/high-resolution mass spectrometry and dioxinresponsive chemically activated luciferase expression are complementary.

Once we get the results of chemical analysis and/or biological assay for dioxin-like compounds in the serum, how to integrate them into the diagnosis? In other words, is there a minimum threshold value beyond which the cutaneous syndrome can be diagnosed? According to an IARC monograph on the evaluation of carcinogenic risks to humans, where data on chloracne were gathered, no sign of chloracne was observed for serum TEQ values below 1,000 pg TEQ/g lipid weight, which corresponds to 50 times the level of that of the general population [7], whereas signs of chloracne were always found beyond $10,000 \mathrm{pg} T E Q / g$ lipid weight [8]. Thus, due to interindividual variability of sensitivity to dioxin-like compounds, and maybe the fact that specialized structures concentrate these compounds, it is difficult to diagnose chloracne on the sole basis of serum TEQ values. This problem is well illustrated by the report of Passarini et al. [1], in which several cases of chloracne syndrome diagnosed on acceptable clinical and histological criteria had serum TEQ values in the normal range, i.e. $5.39 \mathrm{pg}$ TEQ/g lipid weight. This highlights the need for other biomarkers of the cutaneous syndrome promoted by dioxin-like compounds. A recent case of severe dioxin exposure [4] has provided important information on how modern methods of analysing system biology markers in the organ may help solve this question [Saurat et al., in preparation].

Analyses of sporadic cases such as those reported by Passarini et al. with such techniques are mandatory in order to revisit the threshold of pathological dioxin-like exposure in humans and, more precisely, better define the 'no-effect level'. 


\section{References}

1 Passarini B, Infusino SD, Kasapi E: Chloracne: still cause for concern. Dermatology DOI: $10.1159 / 000290694$.

2 Panteleyev AA, Thiel R, Wanner R, Zhang J, Roumak VS, Paus R, Neubert D, Henz BM, Rosenbach T: 2,3,7,8-Tetrachlorodibenzo- $p$ dioxin (TCCD) affects keratin 1 and keratin 17 gene expression and differentially induces keratinization in hairless mouse skin. J Invest Dermatol 1997;108:330-335.

3 Suskind RR: Chloracne, 'the hallmark of dioxin intoxication'. Scand J Work Environ Health 1985;11:165-171.
4 Sorg O, Zennegg M, Schmid P, Fedosyuk R, Valikhnovskyi R, Gaide O, Kniazevych V, Saurat JH: 2,3,7,8-Tetrachlorodibenzop-dioxin (TCCD) poisoning in Victor $\mathrm{Yu}$ shchenko: identification and measurement of TCCD metabolites. Lancet 2009;374: 1179-1185.

5 Taylor JS: Environmental chloracne: update and overview. Ann NY Acad Sci 1979;320: 295-307.

6 Windal I, Denison MS, Birnbaum LS, Van Wouwe N, Baeyens W, Goeyens L: Chemically activated luciferase gene expression (CALUX) cell bioassay analysis for the estimation of dioxin-like activity: critical parameters of the CALUX procedure that impact assay results. Environ Sci Technol 2005; 39:7357-7364.
7 Fromme H, Albrecht M, Boehmer S, Buchner K, Mayer R, Liebl B, Wittsiepe J, Bolte G: Intake and body burden of dioxin-like compounds in Germany: the INES study. Chemosphere 2009;76:1457-1463.

8 IARC Monograph on the Evaluation of Carcinogenic Risks to Humans: Polychlorinated Dibenzo-Para-Dioxins and Polychlorinated Dibenzofurans. Lyon, IARC, 1997, p 69. 